\title{
Ethical Leadership in College Athletics
}

\author{
Peter Paul Roby \\ Northeastern University
}

I finished the first draft of this article after attending the NCAA Convention in San Diego where I spent parts of two days engaged in a dialogue about the future of Division I governance. At that dialogue I took the opportunity to highlight my disappointment over Louisville's hiring of Bobby Petrino as their football coach after his disgraceful exit from the same position at Arkansas. The message sent by Louisville is that winning football games is more important than character, integrity, or values. In his important book Organizational Culture, How Leaders Embed Culture, Edgar Schein highlights that leaders embed the culture of their organizations by what they pay attention to. They embed culture by who they hire and why they fire. How can Louisville ask their students, athletes, staff, and faculty to act with integrity when they hire a coach with this type of background? It has nothing to do with education and little to do with leadership. The message I took from the Petrino hiring is Louisville is more interested in winning football games than reinforcing values about leadership and integrity.

\section{Values}

The Petrino hiring underscores what plagues some of college athletics . . . we say one thing and do another. We can't have values of convenience. We must have values of conviction. When the stakes are highest-we must not blink. That is the truest test of Values-Driven Leadership.

My dad was my best friend growing up. We shared a love of sports and spent many hours together on the practice courts, in the car coming home from games, at the restaurant talking about how I played, about school, about life and about people. He was the most ethical and honest person I have ever met and the lessons he taught me continue to influence me every day of my life. Most of what I am and do is to honor my dad.

My dad worked in a factory for 42 years. He worked on machine called a "hammer," which was used to pound steel into form for use in jet engines and other machines. He worked in the forge room where he would pull hot steel out of the ovens and pound it into shape with the hammer before the hot steel cooled and hardened. Imagine doing that job in those conditions for 42 years. My dad never complained and showed up every day for work so he could provide for his 
family. He loved sports and was quite an athlete growing up and through adulthood. He encouraged my interest in sport and was always there to watch me play or practice. He instilled in me a love of sport but most importantly the importance of sportsmanship and controlling my behavior.

He made a point at an early age that I should never show up the umpire or official with my antics regardless of whether I thought the call was a bad one. I was a talented baseball player in my hometown of New Britain, Connecticut, and threw pretty hard at that age. I was pitching in a little league game one day and thought the umpire was squeezing the strike zone on me so I showed my displeasure with some of his calls. After the inning was over I made my way around the backstop to get a drink from the water fountain when my dad approached and told me if he saw me act that way again he would walk on to the field and pull me off. He told me I needed to respect the umpire and respect my family enough to control my emotions. It was a powerful lesson about values and behavior that I have not forgotten even after 45 years.

We have such an incredible opportunity to teach valuable life lessons to our students and athletes through sport if we only appreciate it and make it the focus of why we want to lead in sport.

Of all the things my dad taught me, the importance of having a strong set of values was most important. He wanted me to respect others and demand respect in return. He never wanted me to think I was better than anyone but never to allow others to make me feel less than. As a young boy I complained about feeling discriminated because I was black and told him how angry I was. Instead of fueling my anger, he asked me to understand that most people are taught to feel a certain way about others and that I should force people to question their beliefs after meeting me because of the way that I carried myself and treated them. By not reacting negatively I would make them question the stereotypes they had been taught by family or friends and perhaps I might change their thinking and contribute more positively to the world. That nugget came from a man with a seventh grade education, who grew up in a segregated society in the 20 s and 30 s, served in a segregated military in the 40s, and had so-called friends try to keep him from joining the local golf club because he was black. What a great teacher! My father's example has fueled my values and made me who I am. I have formed a set of values that I take with me to work and return home with every night.

\section{Perspective}

What business are we in as college coaches or administrators? That is a fundamental question and depending on your answer, it will go a long way in determining the decisions you make in your role in college athletics. If your aim is true and the perspective you bring to this work is one of educator and mentor, then the decisions you will make will be ethical. If your perspective is driven by a desire for a title, lifestyle, or ego, then the decisions you make in your role will likely reflect your perspective and at times not be ethical or in the best interests of your student-athletes.

When hiring a new employee, I pay particular attention to what they write and say about why they want to work in my organization. Why do they want to work in college athletics? What is their personal story about competing and what lessons did they learn? Do they talk about education, values, perspective? Only if these things 
are mentioned somewhere in the course of their application, cover letter, or interview will I be interested enough to consider them for my organization. Ultimately I want to work with people who share my values and my commitment to educating young people through sport. I want people motivated by the right things who will make ethical decisions on behalf of our student-athletes because their aim is true.

It is disappointing to read or hear about another person in a leadership role acting in an unethical manner. I would hope that we would learn from other's mistakes so as not to repeat them. I know that is naive but it still bothers me when I see leaders making the same mistakes that they have obviously read about others making. The controversy in New Jersey is such an example. Several people in Governor Chris Christie's administration decided to tie up traffic on one of the busiest sections of the GW Bridge because they wanted to send a message to local politicians about who was in charge and where their loyalties should lay. No consideration was given to public safety, what was best for taxpayers, missed classes for local school children, thousands of people missing work. Whether they took their orders from the Governor or acted on their own, the question is what business did they think they were in and on whose behalf were they working?

Effective leaders must be willing to observe and reflect on the examples of leadership around them and ask themselves if they would do the same thing and why. We must practice our ethical leadership so we are prepared to make good thoughtful choices when confronted with them. I implore my students in the Master in Sports Leadership program here at Northeastern as well as the participants in the NCAA Pathway program I facilitate for aspiring Athletic Directors to establish their values well before they get to their ultimate leadership position so they feel as though they know what they would do in tough situations long before they arise. Just like when we were athletes in high school or college the repetition of practice to perfect our skills is the same approach we should take when it comes to ethical leadership. Practice every day, read about what others have done and reflect on whether that would work for you. Watch your current boss and how he/she deals with crisis and decision making and reflect on how effective their actions were and if the outcome was appropriate. Practice your leadership skills daily so when the time comes you won't have any crisis of confidence because you are well prepared.

At work I try to treat each person with respect and have worked hard to foster a culture of trust, respect, and integrity. Collegiate athletics requires the highest level of integrity and ethics because we work with 18-22 year olds who are looking for guidance and advice. These students will be influenced by what their coaches and administrators do on a daily basis. We contribute to their education through every interaction, every meeting, every decision that we make. Educating our studentathletes is the business we are in and it must remain in the forefront of all we do.

At the same time those same values must be in action in my private life. I want my actions to set a strong example for my children and be consistent with the values my wife Sandra and I have espoused since they were born. I have watched too many people apologize to their families for their transgressions and say how much it hurts them to know how their actions have hurt and disappointed their family. I always find myself asking if they feel so bad about hurting their family and love them as much as they say they do after getting caught, why didn't their love for their family keep them from making those decisions in the first place? Let's not wait until we get caught doing the wrong thing before we appreciate how lucky we are to have 
the job we have or the family we have. Too many of us get perspective in life after the fact instead of before. Why are we waiting? Who made the rule that living a life of perspective and appreciation is soft or won't result in winning? I'm not buying it and I hope you won't either.

Don't wait until death of a loved one or life threatening illness impacts you or your loved ones before you come to realize what's really important in life. Do it now and appreciate all you have while you can share it with those loved ones.

\section{Purpose}

All of us in college athletics must be inspired by our work. We must appreciate how fortunate we are to have the opportunity to work with talented and dedicated students committed to their education and future. Working on a college campus is inspiring to me and I'm appreciative of the opportunity I have to help shape the futures of our athletes. Working without a purpose is simply a way to make a living. Working with a purpose is rewarding, and motivating. I want to lead by example with how I treat our athletes and respect their opinions. I want to embed a culture of values-driven leadership that puts the interests of the athletes first. I want to prove that ethical leadership in college athletics is alive and well and should be the model for all of us to strive for. It can't just be a sound bite or a part of a document we circulate to staff and students. It must be how we lead each day. It must be the filter through which we see the world.

I played basketball at Dartmouth College for Gary Walters, soon-to-be-retired Athletic Director at Princeton University. When I arrived in the fall of 1975, freshmen were not allowed to play on the varsity in the Ivy League. That rule would change in 1977. As such, I was a starter on our freshmen team and then again as a sophomore on the varsity. As our talent level improved, I played less and as a senior and co-captain I played in only seven games. The interesting thing is that Gary made me feel like I had a purpose and a role to play in our team's success. He gave me the responsibility of motivating the second unit, what we used to refer to as the "white knights" because of the white color the reserves wore on our reversible practice jerseys. Gary gave me a purpose for coming to practice and remaining a committed and enthusiastic member of our team. Despite not playing in most of our games, I felt such a sense of pride and accomplishment each time we won because I knew I had done all I could to help my teammates on the court prepare for our opponent. That team won the second most games any Dartmouth team had won in well over a decade and I was proud to be a part of it. Purpose is a powerful motivator.

\section{Values of Conviction}

The best story to illustrate what I mean by values of conviction happened during my career at Reebok. I was the Sr. Director of Performance Sports at the time when the company engaged in a potential employment discussion with the legend of grass roots basketball that started the whole summer basketball craze at Nike. I was acquainted with him and was invited by Paul Fireman and the other members of the senior management team to a meeting in the board room to observe and 
provide my perspective. Later that day my boss, the president of Reebok North America, came to my office to say that the company wanted to make the deal work and wanted to be sure I was okay with it since this new person would be reporting to me. I was not a fan of the strategies being employed by Nike and this person to build brand loyalty for the swoosh, but I also recognized how effective the strategy had proven to be. Nike was and remains the dominant footwear and apparel brand in the world thanks to the marketing around Michael Jordan. The strategies didn't fit with my values about young kids playing summer basketball all over the country for teams in states they didn't even live in while receiving free gear for doing so. I was concerned that the practice was compromising the values of these young kids by leading them to think they should always search for the best deal and put more emphasis on the gear they receive than the coaching they might get from someone who really had their best interest in mind.

Summer coaches were responsible to only the footwear companies who paid them to promote their products by convincing the next great phenom in the eighth or ninth grade to come play for them. It left a bad taste in my mouth and was something I didn't want Reebok to engage in.

As a result, I told my boss that Reebok could do whatever they wanted with regard to this person, but if they hired him I was going to resign. I didn't have another job and I had three young children to support, but I felt so strongly about not participating in this "product-for-hire" strategy that I was prepared to walk away. For whatever reasons, the deal to hire the industry icon did not happen, but six months after I eventually did leave Reebok, the person in question was in fact hired by Reebok. Did my threat to resign have anything to do with the way the whole thing played out? I can't say for sure. What I do know is that I had remained true to my values throughout my 10.5 years at Reebok and can look back at my time there with pride in the integrity I brought to work with me every day.

\section{Conclusion}

Ethical leaders are made over time. I do not believe in the "Natural Born Leader" concept. Ethical leadership is nurtured and encouraged by family, coaches, friends, supervisors and mentors. It can be practiced and reflected on and observed over time. Our leadership can be shaped by watching how others lead and seeing how others react to it. Most importantly, ethical leadership is influenced by the perspective we bring to it and answering the important question .. . "Why do I want to lead?" If we have a purpose and our aim is true, we can lead with integrity and influence the next generation of ethical leaders. 